\title{
Expression of the chemokine receptor CCR5 in psoriasis and results of a randomized placebo controlled trial with a CCR5 inhibitor
}

\author{
Marjan de Groot $\cdot$ Marcel B. M. Teunissen $\cdot$ Jean P. Ortonne $\cdot$ Julien R. Lambert $\cdot$ \\ Jean M. Naeyaert • Daisy I. Picavet · M. Gladys Arreaza • Jason S. Simon • \\ Maarten Kraan · Jan D. Bos · Menno A. de Rie
}

Received: 28 March 2007 / Revised: 18 June 2007 / Accepted: 25 June 2007 / Published online: 24 July 2007

(C) Springer-Verlag 2007

\begin{abstract}
Several reports have indicated that the chemokine receptor CCR5 and its ligands, especially CCL5 (formerly known as RANTES), may play a role in the pathogenesis of psoriasis. The purpose of this investigation was to examine the expression of CCR5 and its ligands in chronic plaque psoriasis and to evaluate the clinical and immunohistochemical effect of a CCR5 receptor inhibitor. Immunohistochemical analysis showed low but significant increased total numbers of CCR5 positive cells in epidermis and dermis of lesional skin in comparison to nonlesional skin. However, relative expression of CCR5 proportional to the cells observed revealed that the difference between lesional and non-lesional skin was only statistically significant in the epidermis for CD3 positive cells and in the dermis for CD68 positive cells. Quantification of mRNA by reverse transcriptase-polymerase chain reaction
\end{abstract}

M. de Groot $(\varangle) \cdot$ M. B. M. Teunissen · D. I. Picavet ·

J. D. Bos · M. A. de Rie

Department of Dermatology, Academic Medical Center,

University of Amsterdam, P.O.Box 22700,

1100 DE Amsterdam, The Netherlands

e-mail: m.degroot@amc.uva.nl

J. P. Ortonne

Hôpital L'Archet II, Nice, France

J. R. Lambert

Department of Dermatology,

University Hospital Antwerp, Edegem, Belgium

J. M. Naeyaert

Department of Dermatology,

Ghent University Hospital, Ghent, Belgium

M. G. Arreaza · J. S. Simon · M. Kraan

Schering-Plough Research Institute,

Kenilworth, NJ USA only showed an increased expression of CCL5 (RANTES) in lesional skin. A randomized placebo-controlled clinical trial in 32 psoriasis patients revealed no significant clinical effect and no changes at the immunohistochemical level comparing patients treated with placebo or a CCR5 inhibitor SCH351125. We conclude that although CCR5 expression is increased in psoriatic lesions, this receptor does not play a crucial role in the pathogenesis of psoriasis.

Keywords Psoriasis - CCR5 - Chemokine inhibitor

\section{Introduction}

Psoriasis is a chronic skin disease affecting approximately $2-3 \%$ of the population worldwide. Despite its common occurrence, the exact pathogenesis of psoriasis remains unclear and adaptations to the pathogenesis of this inflammatory disease are continuing $[4,9,31,35,40,52]$. Although the specific effector cells responsible for the inflammatory process in psoriasis are not known, reported beneficial effects of specific $\mathrm{T}$ cell targeted therapies, such as cyclosporine A, DAB389IL-2 and alefacept support a central role for $\mathrm{T}$ cells in the pathogenesis of psoriasis $[3,5$, $10,13,15,24,25]$. Further investigation on the immunophenotype and cytokine secretion patterns of $\mathrm{T}$ cells have indicated that specifically Th1-cells are involved in psoriasis $[2,32,46]$.

In the many aspects encompassing T-cell homeostasis, the trafficking of $\mathrm{T}$ cells from blood to tissues is thought to be relevant in chronic inflammatory diseases such as psoriasis. Key factors in this migration are chemo-attractant cytokine molecules known as chemokines and their receptors $[30,33,37,38,57,61,62]$. The predominant chemokine receptors expressed on Th1-cells are CCR5 and 
CXCR3 [7, 9, 29, 30, 33, 34, 47, 50]. Besides its preferential expression on Th1 cells, CCR5 is also expressed on monocytes, macrophages, natural killer and dendritic cells: all thought to be significant elements in the pathogenesis of psoriasis $[8,11,12,18,26,27,36,39,41,43,54]$.

The ligands of CCR5 [CCL3, CCL4 and CCL5 (formerly known as MIP1 $\alpha$, MIP1 $\beta$ and RANTES, respectively)] are highly expressed by keratinocytes in psoriatic tissue [19, 22, 42, 48]. Furthermore, it has been demonstrated that the proinflammatory cytokines IFN- $\gamma$ and TNF$\alpha$ can induce the expression of these chemokines [19, 22] and that treatment of psoriasis resulted in a significant decrease of CCL5, as well as a reduction of $\mathrm{CCR}^{+} \mathrm{T}$ cells in the skin $[19,20,58]$.

Several animal models resembling psoriasis have been developed, yet, none of these models imitates psoriasis completely, hence limiting their utility [51]. Investigations by Mack et al. [36] showed a different expression pattern of CCR5 in mice and humans. Additionally, different expression of a single amino acid in the CCR5 molecule between rhesus macaques and humans resulted in a different response to inhibitors of the receptor in the species [6]. Therefore, research on the expression of CCR5 in psoriasis, as well as clinical efficacy of a CCR5 inhibitor, is limited to humans. So far, the data available on the expression of CCR5 in psoriatic skin in humans are not univocal (varying from high to minimal) and were obtained with divergent methods in investigations in which CCR5 was never the main focus [20, 27, 49, 58, 59].

The primary purpose of this study was to determine the expression of CCR5 and its ligands in chronic plaque psoriasis in situ compared to non-lesional skin, through analysis by immunohistochemistry and quantitative reverse transcriptase-polymerase chain reaction (RT-PCR). In order to examine the possibility that CCR5 plays a functional role in the pathogenesis of psoriasis, we also analyzed clinical and immunohistochemical data obtained from lesional and nonlesional skin biopsies of psoriasis patients before and after treatment with a CCR5 inhibitor.

\section{Materials and methods}

\section{Study design and patients}

Lesional and non-lesional skin biopsies were obtained from nine patients with moderate to severe chronic plaque psoriasis, defined by the psoriasis area severity index $(\mathrm{PASI}) \geq 8$. These skin biopsies were analyzed by manual quantification of immunohistochemical double-staining and quantitative RT-PCR. In order to get insight in the possibility of a functional role of CCR5 in the pathogenesis of psoriasis, 34 patients, including the previous 9 patients, participated in an
8 week, randomized, placebo-controlled, parallel group, multi-centre, double-blind clinical trial in which patients received either $50 \mathrm{mg}$ twice daily of the CCR5 inhibitor SCH351125 (23 patients) or matched placebo (11 patients) orally for 28 days, followed by a follow-up period of 4 weeks. During the follow-up period patients were only allowed to use emollients as treatment and on day 56 vital signs, PASI and blood were assessed. Patients were included at the dermatology outpatient departments of four academic hospitals from April 2004 to December 2004. At baseline and the last day of treatment (day 28), lesional biopsies were taken to evaluate the immunohistochemical effect of the CCR5 inhibitor. For this immunohistochemical evaluation, single-stained sections were analyzed with digital image analysis, semi-quantitative analysis (SQA) and confocal scanning microscopy, and double-stained sections on baseline and day 28 were analyzed by manual quantification. To evaluate the clinical effect of the CCR5 inhibitor the PASI was assessed at baseline, day 28 and day 56 .

In all patients, psoriasis was diagnosed at least 12 months prior to enrolment and patients were not allowed to use systemic psoriasis treatment or phototherapy within 4 weeks of study entry. Only emollients were allowed as topical treatment. All other topical anti-psoriasis therapy (e.g. corticosteroids, vitamin D derivates, etc.) had to be stopped 2 weeks before study entry. The protocol was reviewed and approved by the medical ethical committees of all participating centres and all patients gave their written informed consent before enrolment. The study was conducted according to the Declaration of Helsinki principles and is registered at the ISRCT register (http://www.controlled-trials.com/ISCRT14986467).

\section{Biopsies}

Four-millimeter biopsies were taken from the inside border of a target psoriatic plaque, preferentially from a non-sunexposed area. Lesional biopsies from each patient were obtained from the same target lesion, separated by at least $1 \mathrm{~cm}$. The biopsy samples were randomly coded, snap-frozen in Tissue-Tek OCT compound (Sakura Finetek Europe, Zoeterwoude, The Netherlands) by immersion in liquid nitrogen and stored at $-80^{\circ} \mathrm{C}$ until processing. Five-micrometer cryostat sections were cut and mounted on glass slides (Star Frost adhesive slides, Knittelgläser, Braunschweig, Germany), before being stored at $-80^{\circ} \mathrm{C}$ until immunohistochemical staining. For each staining three sections of each biopsy were analyzed to minimize random variation.

\section{Immunohistochemistry}

After fixation of the slides, the endogenous peroxide activity was inhibited with $0.1 \%$ sodium azide and $0.3 \%$ 
hydrogen peroxide in Tris-buffered saline (TBS), before incubating for $15 \mathrm{~min}$ with $10 \%$ normal goat serum in TBS. Next, the sections were incubated for $1 \mathrm{~h}$ at room temperature (overnight at $4{ }^{\circ} \mathrm{C}$ in the case of CCR5) with the primary antibody in $1 \%$ bovine serum albumin (BSA; Sigma-Chemical Co, St. Louis, MO, USA) in TBS. The following mouse anti-human monoclonal antibodies were used: FITC-conjugated anti-CD3 (BD Pharmingen, San Jose, CA, USA), FITC-conjugated-anti CD68 (clone EBM11; Dako), anti-human neutrophil elastase (Dako, Glostrup, Denmark), anti-cytokeratin 8.12 (keratin 16; Sigma, Saint Louis, MO, USA), anti-CD161 (NK-T cells; BD Pharmingen) and anti-CCR5 (CD195; BD Pharmingen). After rinsing with TBS, sections were further incubated with biotin-conjugated goat anti-mouse antibody (Dako) or, in case of CD3 and CD68 staining, with rabbit anti-FITC (Dako) in 10\% normal human serum (NHS) in TBS for 30 min. Following a wash step with TBS, sections were subsequently incubated with horseradish peroxidase (HPR)-conjugated streptavidin (Dako) or, in case of CD3 staining, with HRP-conjugated goat anti-rabbit antibody (Dako), in 1\% BSA in TBS for $30 \mathrm{~min}$. In case of CCR5 staining an amplification step was performed with the TSA biotin system (Perkin Elmer, Boston, MA, USA). Sections were counterstained with Mayer's haematoxylin (Merck, Darmstadt, Germany) and mounted in Kaiser's glycerol gelatine (Merck). Skin sections were double stained with anti-CCR5 together with anti-CD3 or macrophage marker anti-CD68. The double stained sections were manually counted by two independent observers blinded for order, patient and clinical data. Using a $0.5 \times 0.5 \mathrm{~mm}$ ocular grid and at $200 \times$ magnification, single red $\left(\mathrm{CCR}^{+}\right)$, single blue $\left(\mathrm{CD}^{+}\right.$or $\left.\mathrm{CD}^{+} 8^{+}\right)$, and purple double-positive cells were counted in the entire section. The epidermal and dermal regions were separately counted. The results are expressed as the number of double-positive cells $/ \mathrm{mm}^{2}$.

\section{RNA analysis}

RNA was extracted from frozen skin biopsies using the RNeasy mini kit (Qiagen). RNA quantity was assessed by OD at $260 \mathrm{~nm}$ and RNA quality was analyzed by measuring the ratio of 28s and 18s rRNA using the Agilent 2100 bioanalyzer.

\section{Quantitative PCR}

Taqman primers and probes were designed with Primer Express software (ABI), and purchased from ABI. The sequences of the human primers and probes are available upon request. For the human skin tissue, quantitative PCR was carried out with an ABI Prism 7900HT
Sequence Detection System (Applied Biosystems, Foster City, CA, USA). The PCR reactions were prepared using the components from the Invitrogen Platinum Quantitative RT-PCR One-Step kit and assembled according to the manufacturer's instructions (Invitrogen, Carlsbad, CA, USA). The final concentrations of the primers and probe in the PCR reactions were 200 and $100 \mathrm{nM}$, respectively. The RT-PCR reactions for each gene were performed in a single 384-well plate. Separate plates of the same RNAs were used to quantitate 18S RNA as an internal control for RNA quality, and a primer/probe set for the CD4 promotor was used to check the RNAs for genomic contamination. The PCR data was quantitated based on a standard curve generated using fourfold serial dilutions of the target genes. The fourfold dilutions began at $0.25 \mathrm{ng}$, and eight dilutions were used to generate the standard curve. This procedure provides an absolute quantitation of the amount of CCR5 mRNA in a given tissue. Data were analyzed using Sequence Detection Systems software version 1.7 (Applied Biosystems, Foster City, CA, USA).

\section{Digital image analysis}

Single stained sections were randomly coded and analyzed by computer-assisted image analysis as described previously in detail [23]. In short, images were acquired and analyzed using Syndia algorithm on a Qwin based analysis system (Leica, Cambridge, UK). Twenty high power fields per section were analyzed. Positive staining of cellular markers was expressed as positive cells $/ \mathrm{mm}^{2}$.

\section{Semi-quantitative analysis}

For keratinocyte expression of K16 keratin, a semi-quantitative score was done by two independent observers, blinded for order, patient and clinical data, with a standard binocular light microscope (Olympus) at $200 \times$ magnification. The semi-quantitative score ranged from 0 to $4+$. A score of 0 represented no expression, while a score of 4 represented abundant expression in all layers of the epidermis.

\section{Confocal scanning microscope}

Cryosections of $5 \mu \mathrm{m}$ on silanized slides were fixed with acetone and dried at room temperature, and stored at $-80^{\circ} \mathrm{C}$. Sections were incubated in PBS-3\% BSA for 30 min and washed with PBS before all steps. Next, monoclonal anti-human CCR-5 antibody (R\&D Systems, MAB183, clone 45549.11), Texas red immunoglobulins diluted in PBS-3\% BSA (1:100) was applied, followed by application of the primary monoclonal specific antibodies 
CD3 (clone SK7; BD Biosciences), CD4 (clone SK3; BD Biosciences), CD8 (clone DK25, DakoCytomation) or CD68 (clone KP1, DakoCytomation). Next, FITC-conjugated affinipure rabbit anti-mouse $\operatorname{IgG}$ (Jackson, $A=492$, $E=520)$ diluted in PSB-3\% BSA (1:200) was applied and sections were mounted in fluorescent mounting medium (DakoCytomation). Of each double stained slide three pictures were taken with an image definition of 1024/1024 pixels at a magnification of $25 \times$.

\section{Sample size calculation}

The randomized placebo controlled clinical trial was targeted to randomize a total of 30 subjects (20 on active treatment and 10 on placebo). With this sample size, the trials would be able to detect a difference of $38 \%$ in the response rate from the placebo group assuming a $0 \%$ response rate in the placebo group with $80 \%$ power at an alpha level of 0.05 (two-sided test).

\section{Randomization}

Randomization was stratified by sites. Each site was assigned a fixed number of subjects numbers; e.g. site 1 would get numbers 1-9 and so on. Once the physician of the study site would enroll a subject, the subject would be assigned the next available subject number assigned to the site, starting with the bottom of the list; e.g. the first subject enrolled in site 1 would get number 1, the second subject would get number 2 , and so on. Treatments would be assigned in an active to placebo ratio of $2: 1$ according to a computer generated randomization schedule. No stratification based on age, sex or other characteristics was performed. Throughout the study both patient and treating physician were blinded to the group assignment.

\section{Statistical analysis}

We used SPSS 12.0.1 for Windows (SPSS, Chicago, IL, USA) for the statistical analysis of clinical data. The Mann-Whitney test was used to compare lesional and non-lesional skin at baseline and to compare skin biopsies before and after treatment. All statistical tests were two-sided: $P$ values less than 0.05 were considered significant. The results are expressed as median \pm standard error of the mean. To evaluate the clinical effect of treatment with a CCR5 inhibitor, an intention to treat analysis was performed. Quantitative PCR data analysis was performed by two-sided $t$ test as implemented by Graphpad Prizm (version 4.0 Graphpad Software, San Diego, CA, USA). A $P$ value less than 0.05 was considered significant.

\section{Results}

Comparison of CCR5 expression in lesional versus non-lesional psoriatic skin

The expression of CCR5 in T cells (CD3) and macrophages (CD68) in lesional and non-lesional skin of nine psoriasis patients was compared at baseline. We observed a clear expression of CCR5 which was primarily present in the dermis. In absolute numbers approximately half of the $\mathrm{T}$ cells and half of the macrophages co-expressed CCR5 (Fig. 1). The $\mathrm{CD}^{+} \mathrm{CCR}^{+}$and $\mathrm{CD} 68^{+} \mathrm{CCR}^{+}$double positive cells showed a low but statistically significant increased expression of CCR5 in epidermis and dermis of lesional skin in comparison to non-lesional skin, as shown in Fig. 1. Focussing on the expression of CCR5 as the percentage of all $\mathrm{T}$ cells or macrophages present in the sections, the difference between lesional and non-lesional skin was only statistically significant in the epidermis for $\mathrm{CD}^{+}$ cells $(P<0.05)$ and in the dermis for $\mathrm{CD}^{+}$cells $(P<0,001)$.

Quantitative RT-PCR analysis indicated no increased expression of mRNA for CCR5 and CCR5-ligand CCL4 (MIP-1 $\beta$ ) in lesional skin (Fig. 2), only the expression of CCR5-ligand CCL5 (RANTES) and IL-8 was significantly increased in lesional skin $(P<0.0001$ and $P<0.05)$. The well-known enhanced expression of IL-8 in psoriatic skin was included as positive control.

Lack of clinical efficacy of SCH351125: a CCR5 inhibitor

In total 34 patients were randomized, as shown in Fig. 3 . The demographical data of the patients are shown in Table 1. With regards to co-morbidities, one patient had hypercholesterolemia and one had obesity in the placebo group. In the SCH351125 group one patient also had obesity and two had a history of hypertension. After treatment with the CCR5 inhibitor there was no change in mean PASI in the SCH351125 group $(n=23)[15.5 \pm 3.8$ at baseline, $15.4 \pm 7.4$ at day 28 (Fig. 4a)]. Three of the patients treated with $\mathrm{SCH} 351125(13 \%)$ attained an improvement of $50 \%$ or more compared to baseline (PASI 50 responders), showing improvements of 67, 77 and $69 \%$. In the placebo group $(n=9)$ the mean PASI slightly decreased (14.2 \pm 4.7 at baseline, $12.9 \pm 3.7$ at day 28$)$. None of the patients treated with placebo showed an improvement of more than 50\%. All changes observed were not statistically significant. In the follow-up period no changes in mean PASI were seen in either treatment groups.

In the treatment group four patients discontinued. One patient developed an erythrodermic eruption after 4 days of treatment, which was considered by the site physician as a 
Fig. 1 Immunohistochemical analysis of CCR5 in lesional versus non-lesional skin. Data are shown as mean $\pm \mathrm{SD}$; $n s$ nonsignificant, $* P<0.05$,

$* * P<0.01, * * * P<0.001$
Fig. 2 mRNA analysis of CCR5 in lesional psoriatic skin in comparison with non-lesional skin. IL-8 is used as a control marker. $* P<0.0001$,

$* * P<0.05$
A

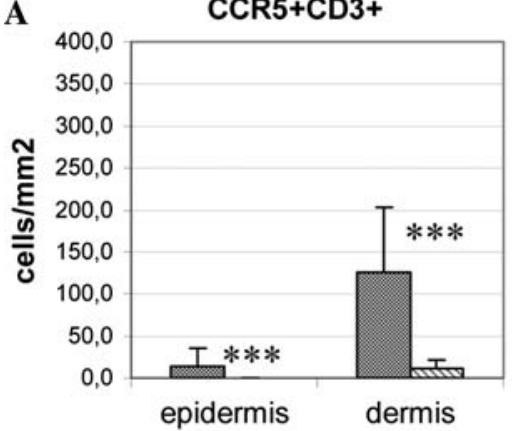

C

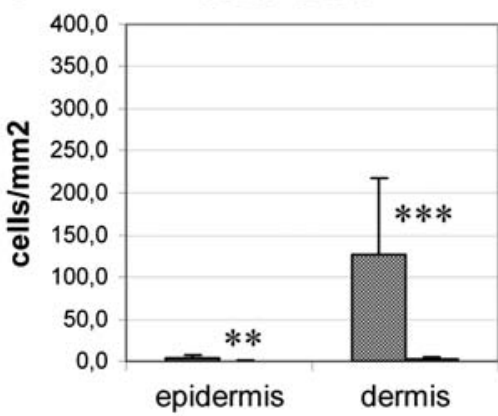

E percentage CCR5+ in relation to $\mathrm{CD} 3+$

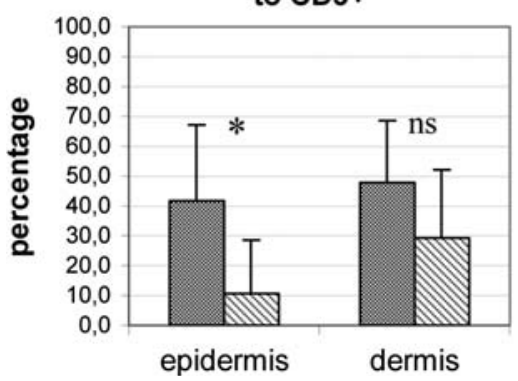

F percentage CCR5+ in relation to CD68+

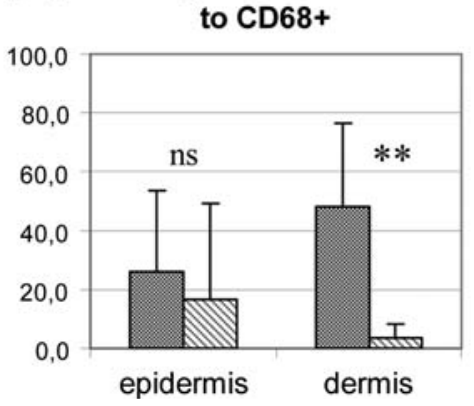

D CCR5-CD68+
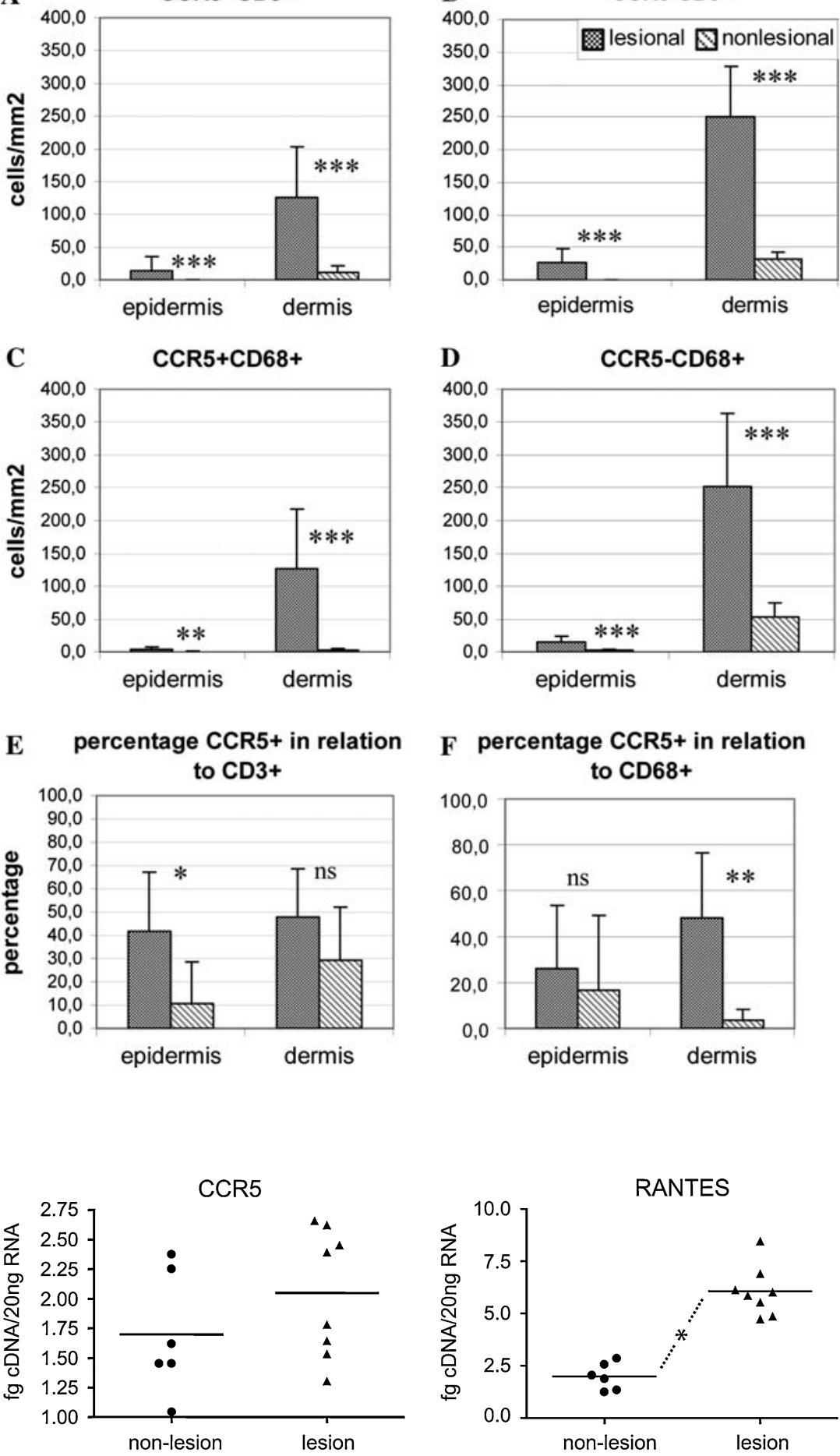

MIP-1 $\beta$

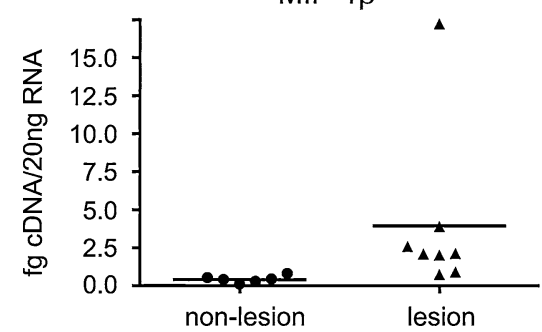

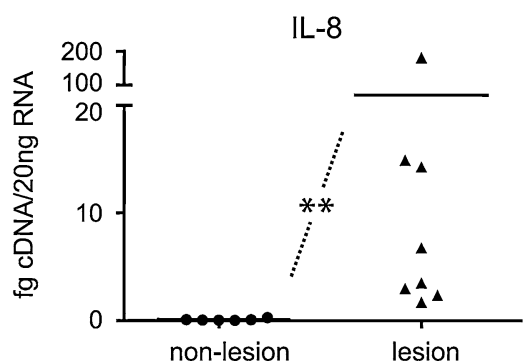




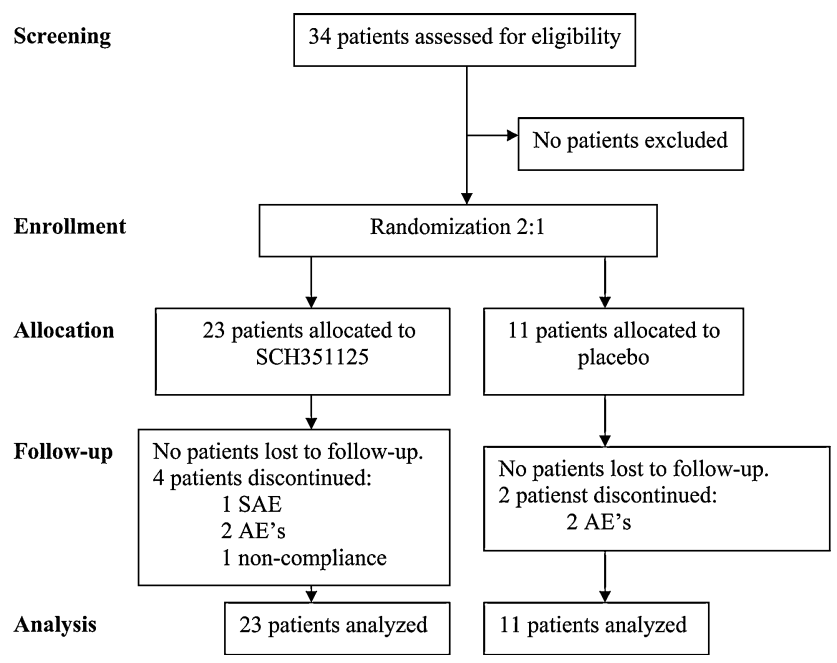

Fig. 3 Flow chart of randomized, placebo controlled clinical trial. $S C H 351125$ CCR5 ligand inhibitor, $S A E$ serious adverse event, $A E$ adverse event

Table 1 Demographical data patients

\begin{tabular}{|c|c|c|}
\hline & \multicolumn{2}{|c|}{ Randomized clinical trial } \\
\hline & Placebo & SCH351125 \\
\hline Number & 11 & 23 \\
\hline Male:female & $7: 4$ & $18: 5$ \\
\hline Age $(\text { years })^{\mathrm{a}}$ & $41.8(10.2)$ & $49.4(14.3)$ \\
\hline Duration of skin disease (years) ${ }^{\mathrm{a}}$ & $20.6(9.8)$ & $19.8(11.6)$ \\
\hline Baseline PASI $^{\mathrm{a}}$ & $14.9(4.7)$ & $15.7(4.3)$ \\
\hline
\end{tabular}

${ }^{\text {a }}$ Mean $( \pm \mathrm{SD})$

SCH351125 CCR5 ligand inhibitor, PASI psoriasis area and severity index, $B S A$ body surface area

serious adverse event (SAE). Two patients discontinued due to adverse events (AEs): one developed shingles in the n.trigeminus area of the right side of his face after 8 days of treatment and one patient discontinued due to hair loss after 21 days of treatment. One patient discontinued due to noncompliance. In the placebo group two patients discontinued due to AEs: both exacerbation of their psoriasis after 2 weeks of treatment.

\section{CCR5 expression before and after treatment} with SCH351125

Immunohistochemical analysis of lesional tissue samples from the SCH351125 group and the placebo group revealed no statistically different expression of CCR5 between baseline and day 28 in both treatment groups, as illustrated by Fig. 4b, c. When focusing on the markers CD3, CD68, CD161, elastase and K16 in relation to the clinical response, no statistically significant difference after 28 days of treatment with either SCH351125 or placebo was found (Fig. 4d), except for elastase and dermal CCR $5^{+} \mathrm{CD}^{+}$cells, which were statistically significantly lowered in the three PASI 50 responders treated with SCH351125. Additional data obtained by confocal scanning microscopy corresponded with the digital image and SQA (data not shown).

\section{Discussion}

The primary objective of this study was to explore the possibility of involvement of CCR5 in the pathogenesis of chronic plaque psoriasis. Therefore we determined the expression of CCR5 in situ at the protein and mRNA level by immunohistochemical analysis and, quantitative RTPCR, respectively. The total number of single positive $\left(\mathrm{CCR}^{+}\right)$and double positive $\left(\mathrm{CCR}^{+} \mathrm{CD}^{+}\right.$and $\mathrm{CCR}^{+} \mathrm{CD} 8^{+}$) cells in lesional psoriatic skin significantly outnumbered those in non-lesional skin. However, when expressed as percentage of CD3 or CD68 cells, the difference between lesional versus non-lesional expression was less clear. With the latter approach we found that the proportion of CCR5 expression was significantly higher in the epidermal $\mathrm{CD}^{+}$cells and dermal $\mathrm{CD}^{+} 8^{+}$cells only, when comparing lesional skin to non-lesional skin.

Analysis of CCR5 mRNA expression demonstrated a slight, though not significant, increased expression of CCR5 in lesional psoriatic skin, perhaps due to the small numbers of patients. In line with earlier observations we found that the mRNA expression for RANTES $[19,48]$ and IL-8 [1, 17, 21, 45, 53] was significantly higher expressed in the lesional samples. However, in contrast to previous research [42] the expression of MIP1 $\beta$ was not increased in lesional psoriatic skin.

In summary, our results do not provide a clear answer to our objective of determining whether the percentage of CCR5 expressing cells is similar in lesional and nonlesional skin, or if this percentage is increased in lesional skin.

To assess any possible functional participation of CCR5 in the development or maintenance of psoriatic plaques we investigated the clinical response to treatment with a CCR5 inhibitor as well as the effect of this drug on the inflamed skin in situ. The randomized placebo-controlled clinical trial revealed no significant clinical effect and changes at the immunohistochemical level between patients treated with placebo or the CCR5 inhibitor. The specific type and dose of the CCR5 inhibitor used in this clinical trial has proven its efficacy previously in vitro, in vivo and clinical studies with other diseases in which CCR5 is known to play a pivotal or significant role $[14,44,55,56,60]$. However, only three patients treated with the CCR5 inhibitor demonstrated a clinical improvement of $50 \%$ or more. It cannot be 
Fig. 4 Clinical and immunohistochemical respons after treatment with a CCR5 receptor inhibitor. In a randomized placebo controlled clinical trial 34 psoriasis patients were randomized for treatment with a CCR5 receptor inhibitor (SCH351125) or placebo for 28 days. Clinical efficacy was measured by psoriasis area and severity index ( $P A$ $S I)$ (a). Lesional skin biopsies were taken from all patients at baseline and day 28 to evaluate immunohistochemical effect. Immunohistochemical single staining of CCR5 of a patient treated with SCH351125 at baseline (b) and day 28 (c). Immunohistochemical markers in relation to clinical response (d). PASI 50 non-responder, improvement of PASI of less than 50\%; PASI 50 responder, improvement of PASI of 50 or more percent; data are shown as mean $\pm \mathrm{SD}$; $n s$ non-significant; ${ }^{1} P=0.05$
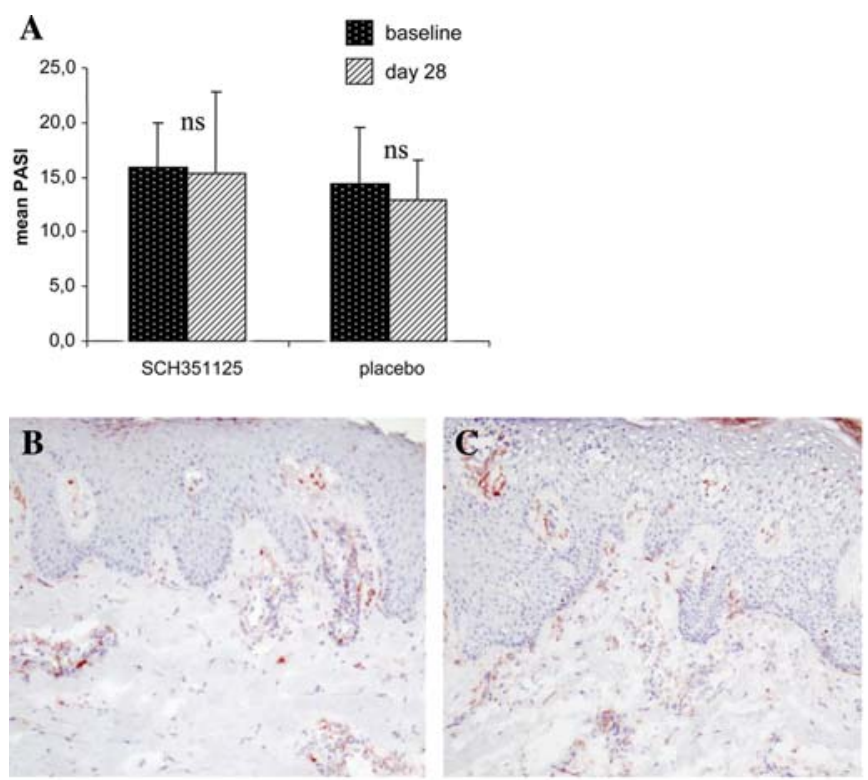

\begin{tabular}{|c|c|c|c|c|c|}
\hline \multirow[t]{3}{*}{$\mathbf{D}$} & \multirow[b]{3}{*}{$n$} & \multicolumn{2}{|c|}{ PASI 50 non-responders } & \multicolumn{2}{|c|}{ PASI 50 responders } \\
\hline & & Baseline & Day 28 & Baseline & Day 28 \\
\hline & & 11 & 11 & 0 & 0 \\
\hline \multirow{9}{*}{ 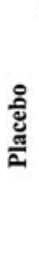 } & CD3 & $105.9 \pm 83.5$ & $102.4 \pm 81.0$ & & \\
\hline & CD161 & $17.3 \pm 26.7$ & $21.5 \pm 32.4$ & & \\
\hline & elastase & $91.5 \pm 90.3$ & $147.6 \pm 179.7$ & & \\
\hline & $\mathrm{K} 16$ & $2.8 \pm 0.3$ & $2.7 \pm 0.3$ & & \\
\hline & CCR5+CD3+ epidermis & $7.5 \pm 4.0$ & $6.0 \pm 4.2$ & & \\
\hline & CCR5+CD3+ dermis & $89.8 \pm 54.0$ & $99.0 \pm 80.9$ & & \\
\hline & CCR5+CD68+ epidermis & $1.8 \pm 1.9$ & $1.2 \pm 1.4$ & & \\
\hline & CCR5+CD68+ dermis & $44.9 \pm 29.0$ & $31.8 \pm 32.3$ & & \\
\hline & $n$ & 18 & 18 & 3 & 3 \\
\hline \multirow{8}{*}{ 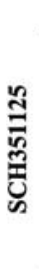 } & CD3 & $108.6 \pm 68.0$ & $113.9 \pm 81.2$ & $45.8 \pm 32.5$ & $56.5 \pm 30.9$ \\
\hline & CD161 & $10.3 \pm 9.5$ & $9.5 \pm 13.2$ & $9.1 \pm 8.0$ & $5.4 \pm 7.0$ \\
\hline & elastase & $40.3 \pm 40.8$ & $52.6 \pm 65.2$ & $24.0 \pm 3.9$ & $4.4 \pm 1.9^{1}$ \\
\hline & $\mathrm{K} 16$ & $3.6 \pm 0.3$ & $3.1 \pm 0.2$ & $3.3 \pm 0.6$ & $2.8 \pm 0.3$ \\
\hline & CCR5+CD3+ epidermis & $13.4 \pm 16.4$ & $11.7 \pm 15.4$ & $7.2 \pm 4.4$ & $3.5 \pm 1.0$ \\
\hline & CCR5+CD3+ dermis & $133.0 \pm 82.5$ & $116.9 \pm 126.5$ & $100.6 \pm 39.0$ & $43.4 \pm 11.9^{1}$ \\
\hline & CCR5+CD68+ epidermis & $2.2 \pm 3.4$ & $2.0 \pm 2.1$ & $1.7 \pm 1.7$ & $1.9 \pm 1.0$ \\
\hline & CCR5+CD68+ dermis & $35.2 \pm 33.2$ & $32.5 \pm 27.1$ & $21.3 \pm 7.6$ & $16.7 \pm 4.8$ \\
\hline
\end{tabular}

excluded that this low and not statistically significant number of patients is due to a spontaneous improvement, reflecting the unpredictability of psoriasis. Surprisingly, the immunohistochemical markers analyzed in the skin biopsies of the so-called PASI 50 responders, did only partially correspond with the clinical response. Of all immunohistochemical markers only elastase and dermal $\mathrm{CCR} 5^{+} \mathrm{CD}^{+}$ showed a significant decline after 28 days of treatment. Notably, the expression of CD3, a marker known to correspond well with the clinical severity as measured by PASI, was increased after treatment with $\mathrm{SCH} 351125$ in two out of the three responding patients (Fig. 4d). In addition, their baseline expression of CD3 was lower in comparison with the other patients while their PASI was similar. This inconsistency could be due to the low number of patients or suggests an individual difference in CD3 kinetics.

The increased expression of CCR5 observed by immunohistochemistry and the increased mRNA expression of CCR5-ligand RANTES in lesional psoriatic skin may suggest an involvement of this receptor and ligand in psoriasis. However, our clinical trial with an effective CCR5 inhibitor unequivocally demonstrated that this is not the case. Previous research has shown increased expression of several chemokines and chemokine receptors in psoriasis, [16, 21, 27, 28, 49] indicating that multiple receptors may participate in regulating $\mathrm{T}$ cell recruitment to the inflamed skin. Furthermore, RANTES is known to also bind with CCR1 and CCR3, whereas MIP1 $\beta$ is solely connected to CCR5. Given this complexity of interactions between chemokines and chemokine receptors, it is not unlikely that blocking a single chemokine receptor (i.e. CCR5) would have been insufficient in diminishing the inflammatory process.

According to Homey [26], chemokine antagonistic approaches to impede with the inflammatory process may perhaps be preventive rather than therapeutic. Chemokines and their receptors play an essential role in the trafficking of $\mathrm{T}$ cells to all kinds of tissue, including the skin. Yet, once 
leucocytes have entered the target organ and underwent activation processes, impairment of recruitment of pathogenic $\mathrm{T}$ cells is likely to be less effective in reducing the clinical symptoms. When combined with a successful eradicative treatment of the $\mathrm{T}$ cells, chemokine antagonists could perhaps be promising candidates for prevention of acute flares, prolongation of lesion-free interval and therefore provide optimized long-term management of patients suffering from chronically relapsing inflammatory skin disease such as psoriasis. So, although CCR5 does not seem to be a key chemokine receptor in the pathogenesis of psoriasis, further efforts are needed to unravel the complete set of chemokines and chemokine receptors significant in the recruitment of inflammatory cells in psoriasis, and may help to identify crucial molecules, as demonstrated previously by TNF in various immune mediated inflammatory diseases.

Acknowledgments We thank Maureen Laverty for her efforts regarding the TaqMan analysis.

\section{References}

1. Arican O, Aral M, Sasmaz S, Ciragil P (2005) Serum levels of TNF-alpha, IFN-gamma, IL-6, IL-8, IL-12, IL-17, and IL-18 in patients with active psoriasis and correlation with disease severity. Mediators Inflamm 2005:273-279

2. Austin LM, Ozawa M, Kikuchi T, Walters IB, Krueger JG (1999) The majority of epidermal T cells in Psoriasis vulgaris lesions can produce type 1 cytokines, interferon-gamma, interleukin-2, and tumor necrosis factor-alpha, defining TC1 (cytotoxic T lymphocyte) and TH1 effector populations: a type 1 differentiation bias is also measured in circulating blood $\mathrm{T}$ cells in psoriatic patients. J Invest Dermatol 113:752-759

3. Baker BS, Griffiths CE, Lambert S, Powles AV, Leonard JN, Valdimarsson H, Fry L (1987) The effects of cyclosporin A on T lymphocyte and dendritic cell sub-populations in psoriasis. $\mathrm{Br} \mathrm{J}$ Dermatol 116:503-510

4. Barker JN (1991) The pathophysiology of psoriasis. Lancet 338:227-230

5. Bata-Csorgo Z, Hammerberg C, Voorhees JJ, Cooper KD (1995) Intralesional T-lymphocyte activation as a mediator of psoriatic epidermal hyperplasia. J Invest Dermatol 105:89S-94S

6. Billick E, Seibert C, Pugach P, Ketas T, Trkola A, Endres MJ, Murgolo NJ, Coates E, Reyes GR, Baroudy BM, Sakmar TP, Moore JP, Kuhmann SE (2004) The differential sensitivity of human and rhesus macaque CCR5 to small-molecule inhibitors of human immunodeficiency virus type 1 entry is explained by a single amino acid difference and suggests a mechanism of action for these inhibitors. J Virol 78:4134-4144

7. Bonecchi R, Bianchi G, Bordignon PP, D'Ambrosio D, Lang R, Borsatti A, Sozzani S, Allavena P, Gray PA, Mantovani A, Sinigaglia F (1998) Differential expression of chemokine receptors and chemotactic responsiveness of type $1 \mathrm{~T}$ helper cells (Th1s) and Th2s. J Exp Med 187:129-134

8. Bonish B, Jullien D, Dutronc Y, Huang BB, Modlin R, Spada FM, Porcelli SA, Nickoloff BJ (2000) Overexpression of CD1d by keratinocytes in psoriasis and CD1d-dependent IFN-gamma production by NK-T cells. J Immunol 165:4076-4085
9. Bos JD, de Rie MA, Teunissen MB, Piskin G (2005) Psoriasis: dysregulation of innate immunity. Br J Dermatol 152:1098-1107

10. Bos JD, Hulsebosch HJ, Krieg SR, Bakker PM, Cormane RH (1983) Immunocompetent cells in psoriasis. In situ immunophenotyping by monoclonal antibodies. Arch Dermatol Res 275:181189

11. Cameron AL, Kirby B, Fei W, Griffiths CE (2002) Natural killer and natural killer-T cells in psoriasis. Arch Dermatol Res 294:363-369

12. Cameron AL, Kirby B, Griffiths CE (2003) Circulating natural killer cells in psoriasis. Br J Dermatol 149:160-164

13. Ellis CN, Krueger GG (2001) Treatment of chronic plaque psoriasis by selective targeting of memory effector $\mathrm{T}$ lymphocytes. $\mathrm{N}$ Engl J Med 345:248-255

14. Este JA (2002) Sch-351125 and Sch-350634. Schering-Plough. Curr Opin Investig Drugs 3:379-383

15. Ferenczi K, Burack L, Pope M, Krueger JG, Austin LM (2000) CD69, HLA-DR and the IL-2R identify persistently activated T cells in psoriasis vulgaris lesional skin: blood and skin comparisons by flow cytometry. J Autoimmun 14:63-78

16. Flier J, Boorsma DM, van Beek PJ, Nieboer C, Stoof TJ, Willemze $\mathrm{R}$, Tensen CP (2001) Differential expression of CXCR3 targeting chemokines CXCL10, CXCL9, and CXCL11 in different types of skin inflammation. J Pathol 194:398-405

17. Flisiak I, Klepacki A, Chodynicka B (2006) Plasma and scales levels of interleukin 18 in comparison with other possible clinical and laboratory biomarkers of psoriasis activity. Biomarkers 11:194200

18. Fraziano M, Cappelli G, Santucci M, Mariani F, Amicosante M, Casarini M, Giosue S, Bisetti A, Colizzi V (1999) Expression of CCR5 is increased in human monocyte-derived macrophages and alveolar macrophages in the course of in vivo and in vitro Mycobacterium tuberculosis infection. AIDS Res Hum Retroviruses 15:869-874

19. Fukuoka M, Ogino Y, Sato H, Ohta T, Komoriya K, Nishioka K, Katayama I (1998) RANTES expression in psoriatic skin, and regulation of RANTES and IL-8 production in cultured epidermal keratinocytes by active vitamin D3 (tacalcitol). Br J Dermatol 138:63-70

20. Ghoreschi K, Thomas P, Breit S, Dugas M, Mailhammer R, van Eden W, van der ZR, Biedermann T, Prinz J, Mack M, Mrowietz U, Christophers E, Schlondorff D, Plewig G, Sander CA, Rocken M (2003) Interleukin- 4 therapy of psoriasis induces Th2 responses and improves human autoimmune disease. Nat Med 9:40-46

21. Gillitzer R, Ritter U, Spandau U, Goebeler M, Brocker EB (1996) Differential expression of GRO-alpha and IL-8 mRNA in psoriasis: a model for neutrophil migration and accumulation in vivo. $\mathrm{J}$ Invest Dermatol 107:778-782

22. Giustizieri ML, Mascia F, Frezzolini A, De Pita O, Chinni LM, Giannetti A, Girolomoni G, Pastore S (2001) Keratinocytes from patients with atopic dermatitis and psoriasis show a distinct chemokine production profile in response to $\mathrm{T}$ cell-derived cytokines. J Allergy Clin Immunol 107:871-877

23. Goedkoop AY, de Rie MA, Teunissen MB, Picavet DI, van der Hall PO, Bos JD, Tak PP, Kraan MC (2005) Digital image analysis for the evaluation of the inflammatory infiltrate in psoriasis. Arch Dermatol Res 297:51-59

24. Gottlieb AB, Grossman RM, Khandke L, Carter DM, Sehgal PB, Fu SM, Granelli-Piperno A, Rivas M, Barazani L, Krueger JG (1992) Studies of the effect of cyclosporine in psoriasis in vivo: combined effects on activated $\mathrm{T}$ lymphocytes and epidermal regenerative maturation. J Invest Dermatol 98:302-309

25. Gottlieb SL, Gilleaudeau P, Johnson R, Estes L, Woodworth TG, Gottlieb AB, Krueger JG (1995) Response of psoriasis to a lymphocyte-selective toxin (DAB389IL-2) suggests a primary immune, but not keratinocyte, pathogenic basis. Nat Med 1:442-447 
26. Homey B (2004) Chemokines and chemokine receptors as targets in the therapy of psoriasis. Curr Drug Targets Inflamm Allergy 3:169-174

27. Homey B, Dieu-Nosjean MC, Wiesenborn A, Massacrier C, Pin JJ, Oldham E, Catron D, Buchanan ME, Muller A, deWaal MR, Deng G, Orozco R, Ruzicka T, Lehmann P, Lebecque S, Caux C, Zlotnik A (2000) Up-regulation of macrophage inflammatory protein-3 alpha/CCL20 and CC chemokine receptor 6 in psoriasis. J Immunol 164:6621-6632

28. Kulke R, Bornscheuer E, Schluter C, Bartels J, Rowert J, Sticherling M, Christophers E (1998) The CXC receptor 2 is overexpressed in psoriatic epidermis. J Invest Dermatol 110:90-94

29. Kunkel EJ, Boisvert J, Murphy K, Vierra MA, Genovese MC, Wardlaw AJ, Greenberg HB, Hodge MR, Wu L, Butcher EC, Campbell JJ (2002) Expression of the chemokine receptors CCR4, CCR5, and CXCR3 by human tissue-infiltrating lymphocytes. Am J Pathol 160:347-355

30. Kunkel EJ, Butcher EC (2002) Chemokines and the tissue-specific migration of lymphocytes. Immunity 16:1-4

31. Lebwohl M (2003) Psoriasis. Lancet 361:1197-1204

32. Lew W, Bowcock AM, Krueger JG (2004) Psoriasis vulgaris: cutaneous lymphoid tissue supports T-cell activation and "Type 1" inflammatory gene expression. Trends Immunol 25:295-305

33. Loetscher P, Moser B, Baggiolini M (2000) Chemokines and their receptors in lymphocyte traffic and HIV infection. Adv Immunol 74:127-180

34. Loetscher P, Uguccioni M, Bordoli L, Baggiolini M, Moser B, Chizzolini C, Dayer JM (1998) CCR5 is characteristic of Th1 lymphocytes. Nature 391:344-345

35. Lowes MA, Bowcock AM, Krueger JG (2007) Pathogenesis and therapy of psoriasis. Nature 445:866-873

36. Mack M, Cihak J, Simonis C, Luckow B, Proudfoot AEI, Bruhl H, Frink M, Anders HJ, Vielhauer V, Pfirstinger J, Stangassinger M, Schlondorff D (2001) Expression and Characterization of the chemokine receptors CCR2 and CCR5 in mice. J Immunol 166:4697-4704

37. Murdoch C, Finn A (2000) Chemokine receptors and their role in inflammation and infectious diseases. Blood 95:3032-3043

38. Murphy PM, Baggiolini M, Charo IF, Hebert CA, Horuk R, Matsushima K, Miller LH, Oppenheim JJ, Power CA (2000) International union of pharmacology. XXII. Nomenclature for chemokine receptors. Pharmacol Rev 52:145-176

39. Nickoloff BJ, Bonish B, Huang BB, Porcelli SA (2000) Characterization of a $\mathrm{T}$ cell line bearing natural killer receptors and capable of creating psoriasis in a SCID mouse model system. J Dermatol Sci 24:212-225

40. Nickoloff BJ, Nestle FO (2004) Recent insights into the immunopathogenesis of psoriasis provide new therapeutic opportunities. J Clin Invest 113:1664-1675

41. Nickoloff BJ, Wrone-Smith T, Bonish B, Porcelli SA (1999) Response of murine and normal human skin to injection of allogeneic blood-derived psoriatic immunocytes: detection of T cells expressing receptors typically present on natural killer cells, including CD94, CD158, and CD161. Arch Dermatol 135:546-552

42. Nomura I, Gao B, Boguniewicz M, Darst MA, Travers JB, Leung DY (2003) Distinct patterns of gene expression in the skin lesions of atopic dermatitis and psoriasis: a gene microarray analysis. J Allergy Clin Immunol 112:1195-1202

43. Ottaviani C, Nasorri F, Bedini C, de Pita O, Girolomoni G, Cavani A (2006) CD56brightCD16(-) NK cells accumulate in psoriatic skin in response to CXCL10 and CCL5 and exacerbate skin inflammation. Eur J Immunol 36:118-128

44. Palani A, Shapiro S, Clader JW, Greenlee WJ, Blythin D, Cox K, Wagner NE, Strizki J, Baroudy BM, Dan N (2003) Biological evaluation and interconversion studies of rotamers of $\mathrm{SCH}$
351125, an orally bioavailable CCR5 antagonist. Bioorg Med Chem Lett 13:705-708

45. Pietrzak A, Lecewicz-Torun B, Koziol-Montewka M (2000) Plasma level of IL-8 in patients with psoriasis and its correlation with psoriasis area and severity index and the clinical type of the disease. Ann Univ Mariae Curie Sklodowska [Med] 55:261-267

46. Piskin G, Sylva-Steenland RM, Bos JD, Teunissen MB (2004) T cells in psoriatic lesional skin that survive conventional therapy with NB-UVB radiation display reduced IFN-gamma expression. Arch Dermatol Res 295:509-516

47. Qin S, Rottman JB, Myers P, Kassam N, Weinblatt M, Loetscher M, Koch AE, Moser B, Mackay CR (1998) The chemokine receptors CXCR3 and CCR5 mark subsets of T cells associated with certain inflammatory reactions. J Clin Invest 101:746-754

48. Raychaudhuri SP, Jiang WY, Farber EM, Schall TJ, Ruff MR, Pert CB (1999) Upregulation of RANTES in psoriatic keratinocytes: a possible pathogenic mechanism for psoriasis. Acta Derm Venereol 79:9-11

49. Rottman JB, Smith TL, Ganley KG, Kikuchi T, Krueger JG (2001) Potential role of the chemokine receptors CXCR3, CCR4, and the integrin alphaEbeta7 in the pathogenesis of psoriasis vulgaris. Lab Invest 81:335-347

50. Sallusto F, Mackay CR, Lanzavecchia A (2000) The role of chemokine receptors in primary, effector, and memory immune responses. Annu Rev Immunol 18:593-620

51. Schon MP (1999) Animal models of psoriasis - what can we learn from them? J Invest Dermatol 112:405-410

52. Schon MP, Boehncke WH (2005) Psoriasis. N Engl J Med 352:1899-1912

53. Schroder JM, Christophers E (1986) Identification of C5ades arg and an anionic neutrophil-activating peptide (ANAP) in psoriatic scales. J Invest Dermatol 87:53-58

54. Sozzani S, Allavena P, Vecchi A, Mantovani A (2000) Chemokines and dendritic cell traffic. J Clin Immunol 20:151-160

55. Stephenson J (2002) Researchers explore new anti-HIV agents. JAMA 287:1635-1637

56. Strizki JM, Xu S, Wagner NE, Wojcik L, Liu J, Hou Y, Endres M, Palani A, Shapiro S, Clader JW, Greenlee WJ, Tagat JR, McCombie S, Cox K, Fawzi AB, Chou CC, Pugliese-Sivo C, Davies L, Moreno ME, Ho DD, Trkola A, Stoddart CA, Moore JP, Reyes GR, Baroudy BM (2001) SCH-C (SCH 351125), an orally bioavailable, small molecule antagonist of the chemokine receptor CCR5, is a potent inhibitor of HIV-1 infection in vitro and in vivo. Proc Natl Acad Sci USA 98:12718-12723

57. Thelen M (2001) Dancing to the tune of chemokines. Nat Immunol 2:129-134

58. Uchida T, Suto H, Ra C, Ogawa H, Kobata T, Okumura K (2002) Preferential expression of Th2-type chemokine and its receptor in atopic dermatitis. Int Immunol 14:1431-1438

59. Vestergaard C, Deleuran M, Gesser B, Gronhoj LC (2003) Expression of the T-helper 2-specific chemokine receptor CCR4 on CCR10-positive lymphocytes in atopic dermatitis skin but not in psoriasis skin. Br J Dermatol 149:457-463

60. Vierboom MP, Zavodny PJ, Chou CC, Tagat JR, Pugliese-Sivo C, Strizki J, Steensma RW, McCombie SW, Celebi-Paul L, Remarque E, Jonker M, Narula SK, Hart B (2005) Inhibition of the development of collagen-induced arthritis in rhesus monkeys by a small molecular weight antagonist of CCR5. Arthritis Rheum 52:627-636

61. Wymann MP, Zvelebil M, Laffargue M (2003) Phosphoinositide 3-kinase signalling-which way to target? Trends Pharmacol Sci 24:366-376

62. Yoshie O, Imai T, Nomiyama H (2001) Chemokines in immunity. Adv Immunol 78:57-110 